\title{
Shock Compressed Solids on the Nova Laser
}

D. H. Kalantar, B. A. Remington, J. D. Colvin,

D. M. Gold, K. O. Mikaelian,

S. V. Weber, and L. G. Wiley

This paper was prepared for submittal to the

11th Topical Conference on Shock Compression of Condensed Matter

Snowbird, Utah

June 27 - July 2, 1999

August 3, 1999

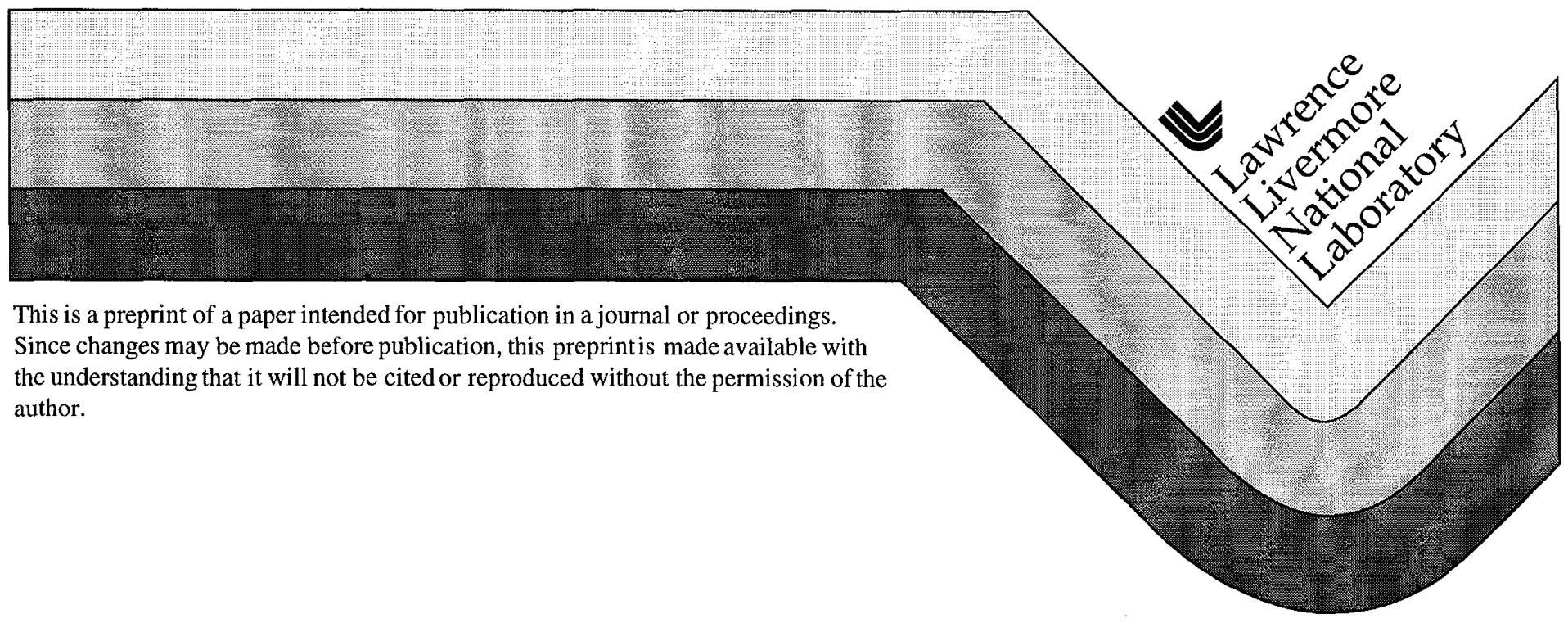




\section{DISCLAIMER}

This document was prepared as an account of work sponsored by an agency of the United States Government. Neither the United States Government nor the University of California nor any of their employees, makes any warranty, express or implied, or assumes any legal liability or responsibility for the accuracy, completeness, or usefulness of any information, apparatus, product, or process disclosed, or represents that its use would not infringe privately owned rights. Reference herein to any specific commercial product, process, or service by trade name, trademark, manufacturer, or otherwise, does not necessarily constitute or imply its endorsement, recommendation, or favoring by the United States Government or the University of California. The views and opinions of authors expressed herein do not necessarily state or reflect those of the United States Government or the University of California, and shall not be used for advertising or product endorsement purposes. 
SHOCK COMPRESSED SOLIDS ON THE NOVA LASER*

\author{
D. H. Kalantar, B. A. Remington, J. D. Colvin, D.M. Gold, K. O. Mikaelian, \\ S. V. Weber, L. G. Wiley
}

Lawrence Livermore National Laboratory, Livermore CA 94550

\begin{abstract}
Experiments are being developed to shock compress metal foils in the solid state to study the material strength under high compression. The $\mathrm{x}$-ray drive has been characterized and hydrodynamics experiments performed to study growth of the Rayleigh-Taylor (RT) instability in Al foils at a peak pressure of about 1.8 Mbar. Pre-imposed modulations with an initial wavelength of 10-50 $\mathrm{m}$, and amplitude of $0.5 \mu \mathrm{m}$ show growth. Variation in the growth factors may be a result of shot-shot variation in preheating of the Al sample due to emission from the plasma in the hohlraum target
\end{abstract}

\section{INTRODUCTION}

In a classical fluid model, when a light fluid accelerates a heavier fluid, the interface is Rayleigh-Taylor (RT) unstable. A mass modulation at the embedded material interface is unstable, and can grow when accelerated. In the solid state, however, the strength of the material can counter the effect of the RT instability. The parameters that define whether a material is stable or unstable to instability growth in the solid state depend on the wavelength and amplitude of the modulation, the acceleration, foil thickness, and material properties, such as yield stress, shear modulus, and the acceleration history.

The elastic-plastic behavior that allows instability growth to occur in the solid state is described by a semi-empirical constitutive model ${ }^{1}$. Such plastic flow has been characterized either microscopically by the theory of lattice dislocations, or macroscopically by an effective lattice viscosity ${ }^{2}$.

*This work was performed by Lawrence Livermore National Laboratory under the auspices of the U.S. Department of Energy under Contract No. W-7405-ENG-48
Stability boundaries can be defined, as described by Lebedev et $\mathrm{al}^{3,4}$, to determine whether material strength is sufficient to inhibit plastic deformation and completely stabilize the growth of a modulation. This has been investigated by Barnes et $a l^{5}$ using Al plates with a preimposed surface modulation that are driven with a high explosive drive, and also by Lebedev et $a l^{3,4}$, using $\mathrm{Al}$ and $\mathrm{Ti}$ plates in similar experiments.

We are conducting experiments on the Nova laser ${ }^{6}$ to study the plastic flow of metals at high pressure and very high strain rates. Metal foils of aluminum are compressed by a factor of 1.5-2.0 with staged shocks reaching peak pressures of 1.8 Mbar. The Rayleigh-Taylor instability is the observable "probe" in this experiment, with departures from classical (liquid) behavior characterizing the material strength properties at high pressure and compression.

We present details in this paper of the hohlraum target design and $x$-ray drive characterization. We also present calculations of the material state with this drive, and results from instability growth experiments using thin $\mathrm{Al}$ foils. 


\section{EXPERIMENTAL DETAILS}

The hydrodynamics experiments are conducted using an $\mathrm{X}$-ray drive created in a cylindrical gold hohlraum. The target geometry is shown in Fig. 1. The hohlraum (Fig. 1a) is cylindrically symmetric with internal shielding positioned to prevent preheating of the metal foil due to hard $\mathrm{x}$-rays from $M$-band emission at the laser spots on the inner hohlraum wall. The hohlraum is $3.44 \mathrm{~mm}$ in diameter, and $5.75 \mathrm{~mm}$ long.

The hydrodynamics package (Fig. 1b) mounted to the side of the hohlraum consists of a $20 \mu \mathrm{m}$ thick brominated polystyrene $(\mathrm{CH}(\mathrm{Br}))$ foil pressed in contact with the metal foil. The $\mathrm{CH}(\mathrm{Br})$ ablator has a $2 \%$ atomic $\mathrm{Br}$ fraction to enhance the opacity to the soft $\mathrm{x}$-rays. We typically use $18-20 \mu \mathrm{m}$ thick Al-6061 foils that have been rolled and then machined to have a sinusoidal modulation.

Eight Nova beams generate an $\mathrm{x}$-ray radiation environment in the two laser heated cavities of the target. Re-emitted $\mathrm{x}$-rays that pass through the holes in the internal shields heat the central (x-ray heated) cavity and ablate material from the $\mathrm{CH}(\mathrm{Br})$ ablator, launching a series of shocks into the package to shock compress the metal foil and accelerate it away from the hohlraum.

We diagnose the growth of the perturbed unstable embedded interface by $\mathrm{x}$-ray radiography. We use a large area $(0.7 \mathrm{~mm}$ diameter focal spot) backlighter generated with two additional Nova beams aligned to a separate Sc backlighter foil generating $\mathrm{He}_{\alpha} \mathrm{x}$-rays al $4.3 \mathrm{keV}$, respectively. A 4 ns square laser pulse shape was used for these backlighter beams, and delays relative to the drive beams ranged from $15-20 \mathrm{~ns}$

\section{SHOCK DRIVEN ALUMINUM}

The laser pulse shape is designed to generate an $\mathrm{x}$-ray drive to launch 2 shocks into the Al foil, compressing it at high pressure in the solid state. The pulse shape is shown in Fig. 2. This shape is generated by using 8 beams staggered in time to build a 8.5 ns long laser pulse. We have characterized the $x$-ray drive this creates in the central cavity of the hohlraum target using the Dante diagnostic ${ }^{7}$ and side on foil trajectories. We have also performed full simulations of the drive inside the hohlraum to establish a detailed model

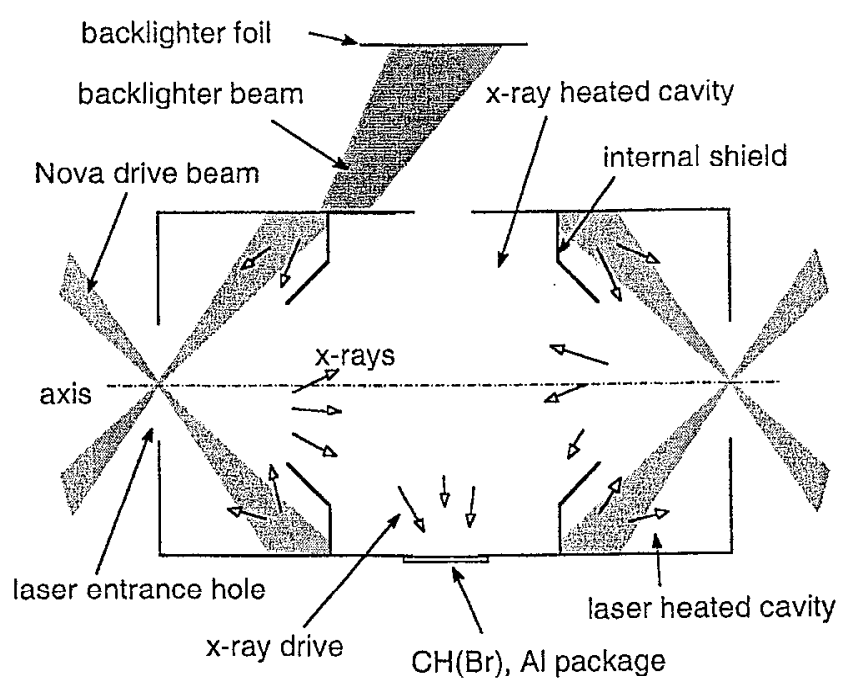

a) Hohlraum target

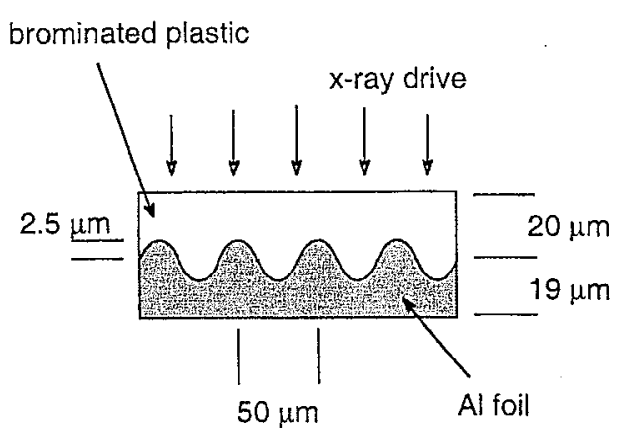

b) Rayleigh-Taylor package

FIGURE 1. Schematic showing the a) the Nova hohlraum target geometry, and b) the RT package consisting of an Al foil and brominated plastic ablator with a preimposed modulation at the cmbedded interface. 
for the drive history.

The Dante diagnostic is an array of absolutely calibrated filtered $\mathrm{x}$-ray detectors. This provided a measurement of the radiation temperature as a function of time. The measured $\mathrm{x}$-ray temperature (uncorrected) is shown overlaid with the laser pulse shape in Fig. 2.

The peak portion of the drive is verified with a side-on foil trajectory measurement. For this, we mounted a package consisting of $20 \mu \mathrm{m} \mathrm{CH}(\mathrm{Br})$ with $18 \mu \mathrm{m} \mathrm{Al}$ on the side of the hohlraum. We recorded an $x$-ray shadow image of the foil as it was accelerated away from the hohlraum using a high magnification $\mathrm{x}$-ray streaked imager. The Al foil moves approximately $140 \mu \mathrm{m}$ after $20 \mathrm{~ns}$. In order to match the overall motion of the foil in the hydrodynamics simulations, the peak of the drive is adjusted by $<5 \%$. This adjustment is interpreted as a correction due to the uncertainty in the opacity of the ablator at low drive temperatures, and in the initial Dante drive measurement itself.

We model the conditions in the foil package with a 1-D hydrodynamics code. The calculated temperature and pressure at the embedded ablator/Al interface are shown in Fig. 3. In these simulations, the first shock due to the low foot is about $0.2 \mathrm{Mbar}$ in the $\mathrm{Al}$, and the main shock due the peak drive is $1.8 \mathrm{Mbar}$. The Atwood number is ahout 0.13 from $6-13 \mathrm{~ns}$, and then it comes up to 0.2 . The time-scale of this experiment is short, and the longitudinal strain rate is about $7 \times 10^{7} \mathrm{~s}^{-1}$. The

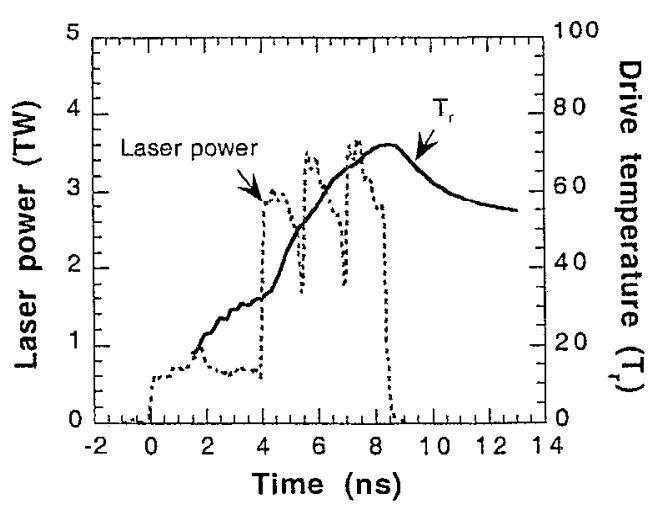

FIGURE 2. Laser pulse shape and uncorrected radiation drive temperature inside the $\mathrm{x}$-ray heated cavity. slow decay of the hohlraum $x$-ray drive maintains the high pressure until about $10 \mathrm{~ns}$. During the expeirment, the interface accelerates to a velocity of about $16 \mu \mathrm{m} / \mathrm{ns}$ at $20 \mathrm{~ns}$. In these simulations, the material temperature at the interface stays below the melt temperature, which we calculate by the Lindemann law:

$$
T_{m}=T_{m o} \exp \{2 a(1-1 / \eta)\} \eta^{2\left(\gamma_{o}-n-1 / 3\right)}
$$

where $T_{m o}$ is the melt temperature at constant volume, $\eta$ is the compression of the sample, $\gamma$ is the Grüneisen gamma, and $a$ is the coefficient of volume dependence of $\gamma$, as defined by Steinberg et al ${ }^{1}$.

The low isentrope drive is calculated to keep the foil very near an isentropic compression throughout the experiment. In Fig. 4 we show the internal energy at the $\mathrm{Al}$ interface plotted as a function of density (compression) from $t=0$ to $t=15 \mathrm{~ns}$. The dotted curve labeled "isetrope" here corresponds to an isentropic compression.

Experiments to characterize preheat of the foil during the foot portion of the drive were done using an optical displacement interferometer ${ }^{8,9,10}$. We measured motion of the back surface of a $17 \mu \mathrm{m}$ thick Al flat target mounted on the side of the hohlraum. Motion due to the shock breakout from the back of the foil is evident by a shift in the fringe pattern, as shown in Fig. 5. The time-resolved

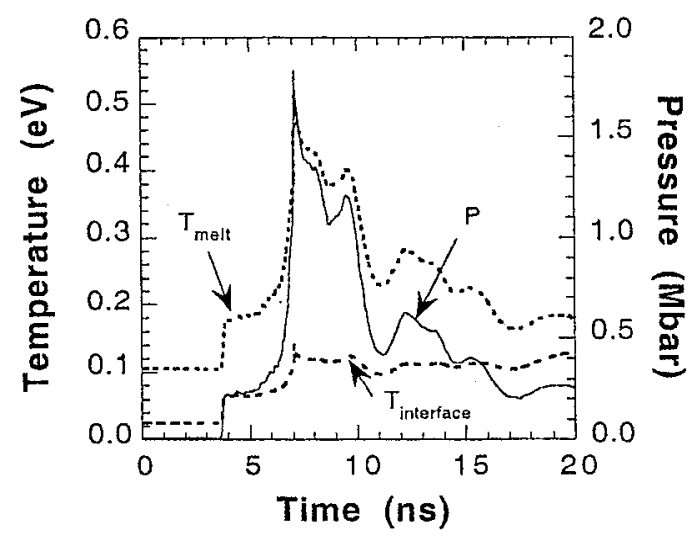

FIGURE 3. Pressure and temperanure calculated at the embedded interface. The melt temperature is shown for reference. 


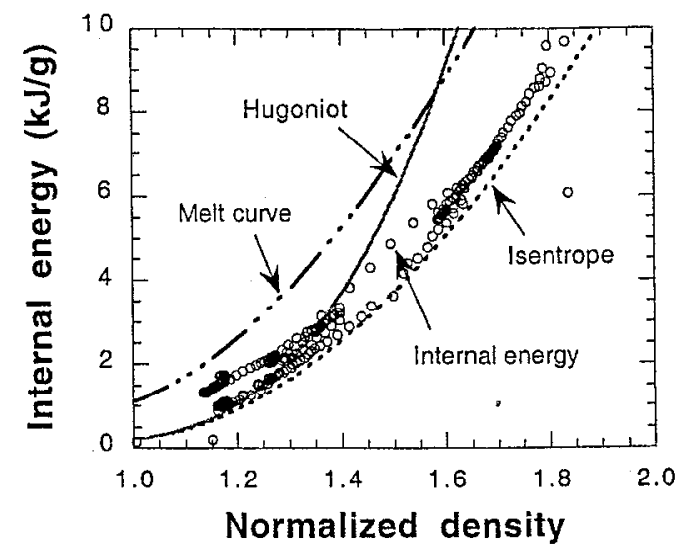

FIGURE 4. Internal energy trajectory for the embedded Al interface. The foil is calculated to remain on a low adiabat.

interferometer data is shown in Fig. 5a, and the analyzed position of the back surface as a function of time is shown in Fig. $5 \mathrm{~b}$.

This diagnostic is highly sensitive to small displacement. The measurement gives a back surface motion of $\sim 1 \mu \mathrm{m}$ in $\sim 2 \mathrm{~ns}$, ie. $0.5 \mu \mathrm{m} / \mathrm{ns}$. This motionmay be due to the breakout of the elastic precursor wave or due to some amount of preheat at the back surface of the $\mathrm{Al}$ foil. The rapid motion and disappearance of the fringes occurs as the main shock breaks out. We show simulated position as a function of time for the back surface

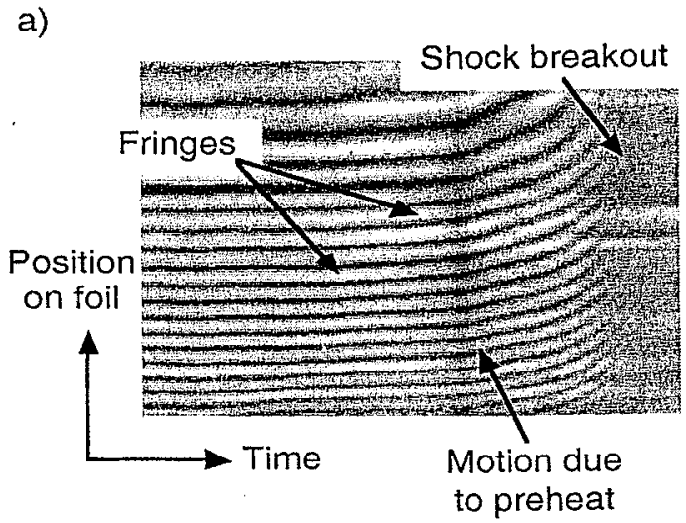

with some imposed preheat to illustrate how this measurement is affected by low preheat levels.

\section{INSTABILITY GROWTH EXPERIMENTS}

Sinusoidal modulations are machined in the $\mathrm{Al}$ foils with amplitudes of $0.5 \mu \mathrm{m}$, and wavelengths of 10,20 and $50 \mu \mathrm{m}$. A $20 \mu \mathrm{m}$ thickness of brominated plastic ablator is pressed onto the modulated foils, and then the package is mounted over a hole in the side of the hohlraum. The x-ray drive ablatively launches a series of shocks to compress and accelcrate the metal foil away from the side of the hohlraum.

Radiographic images of the foil are recorded using $4.3 \mathrm{keV} \mathrm{Sc} \mathrm{x}$-rays. Up to 16 images are recorded on 4 independently timed microchannel plate striplines on each laser shot, using the Flexible X-ray Imager ${ }^{11}$ with a 230 ps gate pulse. The modulation amplitude in optical depth is calculated by Fourier analysis at each time. The Fourier amplitude is normalized to the initial contrast in optical depth, which we measured on a separate shot.

The growth factors for $\lambda=20 \mu \mathrm{m}, 0.5 \mu \mathrm{m}$ amplitude modulations are shown in Fig. 6 . In these experiments, the ablator/metal interface moves about $140 \mu \mathrm{m}$ by $20 \mathrm{~ns}$. When we nurmalize the measurements with the initial contrast at that wavelength, the instrument resolution (MTF $\sim 0.6$ at

b)

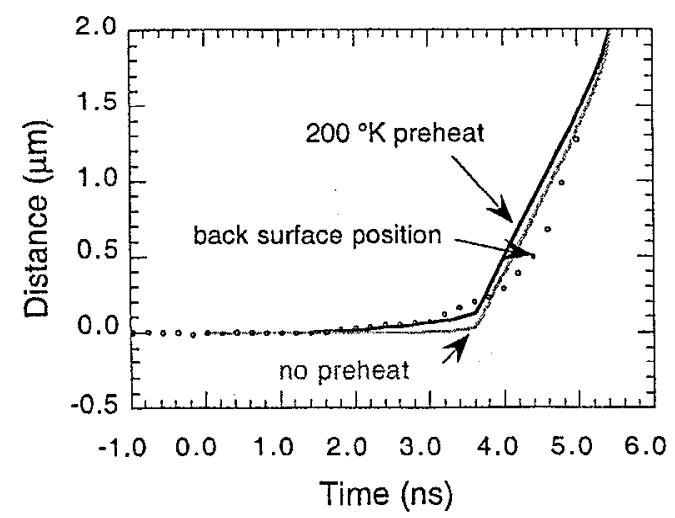

FIGURE 5. a) Streaked record from the optical interferometer showing fringe motion corresponding to motion of the free back surface of the Al foil. b) Position of the back surface of the Al foil as a function of time. Simulations with different levels of preheat are overlaid. 
$12 \mathrm{X}$ for $\lambda=20 \mu \mathrm{m}$ ) is removed from the measurement.

Overlaid on the graphs in Fig. 6, we have plotted the growth factors simulated using both a fluid model, and the constitutive material strength model described by Steinberg et al. The data show significant variation from shot to shot, suggesting that there may be effects such as non-reproducible preheat. In this experiment, emission from the plasma that fills the hohlraum may result in as much as a few tenths of a percent of the $x$-ray flux incident on the package in gold M-band emission. This may be sufficient to heat the $\mathrm{Al}$ so that it melts on shock compression. In order to reduce this effect, we need to be able to better shield the metal foil. In turn, this requires we be able to better measure the preheat due to $\mathrm{x}$-rays using a technique such as the optical interferometer described earlier so modifications to the target design may be tested and optimized.

\section{DISCUSSION}

We have developed an $\mathrm{x}$-ray drive to shock compress metal foils in the solid state using an internally shielded hohlraum with a high contrast shaped laser pulse.

We use a combination of Dante measurements, side-on foil trajectories, and shock timing measurements to develop an understanding of the

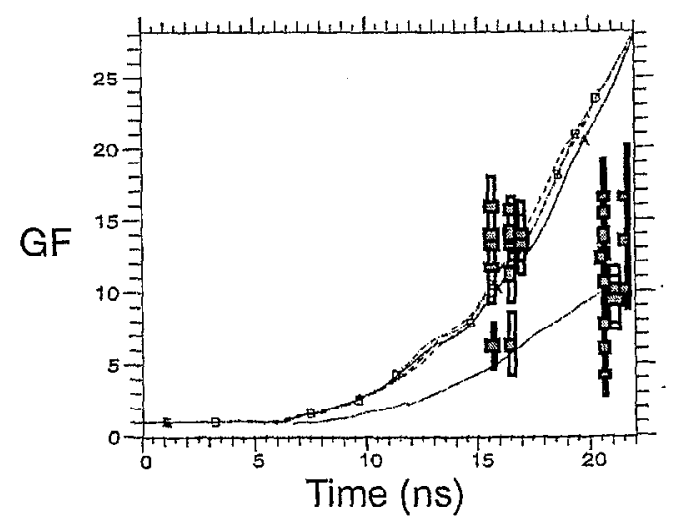

FIGURE 6. Measured growth factors for a $20 \mu \mathrm{m}$ wavelength perturbation. $x$-ray drive. Hydrodynamic experiments that are designed to study growth of the RT instability in the plastic flow regime have been started. We present the growth factors for $20 \mu \mathrm{m}$ wavelength with a $0.5 \mu \mathrm{m}$ preimposed amplitude. The results are senstitive to absolute levels of preheat in the metal foil. This motivates further improvements in diagnostics to measure low levels of preheat.

\section{REFERENCES}

${ }^{1}$ D. J. Steinberg, S. G. Cochran, M. W. Guinan, J. Appl. Phys. 51, 1498 (1980).

${ }^{2}$ L. C. Chhabildas, J. R. Asay, J. Appl. Phys. 50, 2749

(1979).

${ }^{3}$ A. I. Lebedev, P. N. Nizovtsev, V. A. Rayevsky, in the Proceedings of the 4th International Workshop on the Physics of Compressible Turbulent Mixing, 29 March - 1 April, Cambridge, England (Cambridge University Press, 1993), p. 81

${ }^{4}$ A. I. Lebedev, P. N. Nizovtsev, V. A. Rayevsky, V. P. Soloviov, in the Proceedings of the 6th International Workshop on the Physics of Compressible Turbulent Mixing, 17-21 June, 1997, Marseille, France (I.U.S.T.I./C.N.R.S., Marseille, 1997).

${ }^{5}$ J. F. Barnes, P. J. Blewett, R. G. McQueen, K. A. Meyer, D. Venable, J. Appl. Phys. 45, 727 (1974).

${ }^{6}$ E. M. Campbell, J. T. Hunt, E. S. Bliss, D. R. Speck, R. P. Drake, Rev. Sci. Instrum. 57, 2101 (1986).

${ }^{7}$ H. N. Komblum, R. L. Kauffman, J.A. Smith, Rev. Sci. Instrum. 57, 2179 (1986)

${ }^{8}$ K. S. Budil, P. Celliers, G. W. Collins, L. B. DaSilva, R. Cauble, R. J. Wallace, G. Chiu, A. Ng, in the Inertial Confinement Fusion Quarterly Report 7 (1), UCRL-LR105821-97-1, 11 (1997), copies available from the National Technical Information Service, Springfield VA. ${ }^{9}$ G. W. Collins, P. Celliers, L. B. Da Silva, R. Cauble, D. Gold, M. Foord, K. S. Budil, R. Stewart, N. C. Holmes, M. Ross, B. A. Hammel, J. D. Kilkenny, R. J. Wallace, A. Ng, Phys. Plasmas 5, 1864 (1998).

${ }^{10}$ D. M. Gold et al, "Optical interferometry diagnostics in laser-driven equation of state experiments", to be published in Shock Compression in Condensed Matter1999, edited by M.D. Furnish, AIP Conference Proceedings, New York 1999.

${ }^{11}$ K. S. Budil, et al, Rev. Sci. Instrum. 67, 485 (1996). 